WellBeing International

WBI Studies Repository

$7-2004$

\title{
Neuroanatomical Structure of the Spinner Dolphin (Stenella longirostris orientalis) Brain From Magnetic Resonance Images
}

\author{
Lori Marino \\ Emory University \\ Keith Sudheimer \\ Michigan State University \\ William A. McLellan \\ University of North Carolina - Wilmington \\ John I. Johnson \\ Michigan State University
}

Follow this and additional works at: https://www.wellbeingintlstudiesrepository.org/acwp_vsm

Part of the Animal Structures Commons, Animal Studies Commons, and the Veterinary Anatomy Commons

\section{Recommended Citation}

Marino, L., Sudheimer, K., Mclellan, W. A., \& Johnson, J. I. (2004). Neuroanatomical structure of the spinner dolphin (Stenella longirostris orientalis) brain from magnetic resonance images. The Anatomical Record Part A: Discoveries in Molecular, Cellular, and Evolutionary Biology, 279(1), 601-610.

This material is brought to you for free and open access by WellBeing International. It has been accepted for inclusion by an authorized administrator of the WBI Studies Repository. For more information, please contact wbisr-info@wellbeingintl.org.

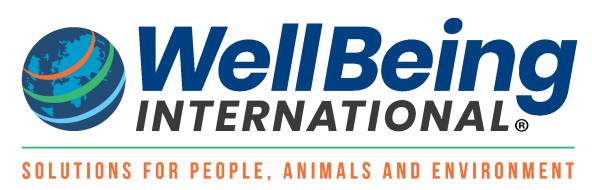




\title{
Neuroanatomical Structure of the Spinner Dolphin (Stenella longirostris orientalis) Brain From Magnetic Resonance Images
}

\author{
Lori Marino $^{1}$, Keith Sudheimer ${ }^{2}$, William A. McLellan ${ }^{3}$, and John I. Johnson ${ }^{2}$ \\ ${ }^{1}$ Emory University \\ ${ }^{2}$ Michigan State University \\ ${ }^{3}$ University of North Carolina at Wilmington
}

\section{KEYWORDS}

spinner dolphin, brain, neuroanatomy, MRI, magnetic resonance imaging

\begin{abstract}
High-resolution magnetic resonance (MR) images of the brain of an adult spinner dolphin (Stenella longirostris orientalis) were acquired in the coronal plane at 55 antero-posterior levels. From these scans a computergenerated set of resectioned virtual images in the two remaining orthogonal planes was constructed with the use of the VoxelView and VoxelMath (Vital Images, Inc.) programs. Neuroanatomical structures were labeled in all three planes, providing the first labeled anatomical description of the spinner dolphin brain.
\end{abstract}

The unusual brain of cetaceans evinces a unique combination of features that are generally dissimilar to those observed in other mammalian brains. These differences are found at the level of the cortical cytological and chemical architecture (Glezer and Morgane, 1990; Glezer et al., 1990, 1992a, b, 1993, 1995a, 1999; Morgane et al., 1990; Hof et al., 1992, 1995, 1999, 2000), cortical surface configuration (Jacobs et al., 1979; Morgane et al., 1980; Haug, 1969), and subcortical structure (Tarpley and Ridgway, 1994; Glezer et al., 1995b; Marino et al., 2000). Furthermore, cetacean brains are highly elaborated and convoluted, and exhibit hyperproliferation of the hemispheres in all regions but the frontal lobe (Morgane et al., 1980).

Magnetic resonance imaging (MRI) has become a valuable method for elucidating normal neuroanatomical structures (Marino et al., 2001a-c, 2002, 2003a, b) and neuropathologies (Ridgway et al., 2002) in several species within the cetacean suborder Odontoceti (i.e., toothed whales, dolphins, and porpoises). MRI allows the visualization of brain structures in a normal three-dimensional (3D) arrangement without histological artifacts and distortions. MRI-based neuroanatomical studies have elucidated a number of similarities and differences across odontocete brains (Marino et al., 2001a-c, 2002, 2003a, b).

Although our knowledge of odontocete brains is increasing, there is essentially no literature regarding the brain of the spinner dolphin (Stenella longirostris). S. longirostris is one of five recognized Stenella 
species within the family Delphinidae. S. longirostris is a gregarious, deepwater species that subsumes several geographical varieties. The species is known for its habit of performing spectacular leaps and spins out of the water. Until now, however, the only published papers referring to the brain of $S$. longirostris have been limited to reports concerning the size of the whole brain and body (Marino, 2002) and the corpus callosum (Tarpley and Ridgway, 1994). There has been no neuroanatomical description of the spinner dolphin brain. In the present work we present the first MRI-based, anatomically-labeled, three-dimensional (3D) description of the brain of a spinner dolphin (Stenella longirostris orientalis).

\section{MATERIALS AND METHODS}

\section{Specimen}

The specimen examined in this study was the postmortem brain of a sexually immature though morphologically adult female eastern spinner dolphin (Stenella longirostris orientalis) (specimen \#SJC010). Mortality occurred in a tuna purse seine net in the eastern tropical Pacific Ocean. The total body length of the specimen was $164.8 \mathrm{~cm}$, and the total body mass was $33.6 \mathrm{~kg}$. Perrin (1975) reported that the total length of female spinner dolphins does not exceed $175 \mathrm{~cm}$; thus, the current specimen was morphologically mature. The specimen was necropsied and the brain was collected within $2 \mathrm{hr}$ postmortem. The whole-brain weight was $450 \mathrm{~g}$ at necropsy. A small biopsy (ca. $2 \mathrm{~g}$ ) of tissue was removed from the convexity of the right hemisphere for contaminant and histopathology analysis. The brain was fixed immediately after necropsy in 10\% neutrally buffered formalin, and the fluids were changed twice during the remainder of the research cruise.

$M R I$

T2-weighted MR images of the entire brain were acquired in the coronal plane (cross-sectional to the major axis of the brain) at 55 anteroposterior levels with a $1.5 \mathrm{~T}$ Philips NT scanner (Philips Medical System, The Netherlands) at Emory University School of Medicine. The scanning sequence included the following parameters: slice thickness $=2.0 \mathrm{~mm}$, slice interval $=0 \mathrm{~mm}$, time to repetition $=3000 \mathrm{msec}$, time to echo $=13 \mathrm{msec}$, number of signals averaged $=2$, field of view $=160 \mathrm{~mm}$, and matrix $=256 \times 256$ pixels.

\section{D Reconstruction and Reformatting}

Computer-generated 3D reconstruction images were created with the use of the software programs VoxelView and VoxelMath (Vital Images, Inc., Plymouth, MN) at the Laser Scanning Microscopy Laboratory at Michigan State University. The 3D-rendered model was then digitally resectioned in orthogonal planes to produce corresponding virtual sections in the horizontal and sagittal planes. The dolphin brain possesses pronounced mesencephalic, pontine, and cervical flexures, and anteroposterior foreshortening of the forebrain, which gives it a forward rotated appearance in the cranium with respect to the beak-fluke axis. However, scanning was done with the brain removed from the cranium, and the alignment of the planes was adjusted so that it closely approximated coronal, horizontal, and sagittal planes in the human brain.

\section{Anatomical Labeling and Nomenclature}

All identifiable anatomical structures of the dolphin brain were labeled in the originally-acquired coronal plane images as well as in the images from the virtual-sectioned brain in the sagittal and horizontal planes. The nomenclature used is from Morgane et al. (1980). The MR images of the spinner dolphin brain were compared with published photographs and illustrations of the bottlenose dolphin brain from Morgane et al. (1980), as well as with published neuroanatomical atlases based on MRI scans of adult 
odontocete brains (Marino et al., 2001b, c, 2002, 2003a, b). The scans were also compared with a complete alternate series of sections of bottlenose dolphin brains that were stained for cell bodies (Nissl method) and myelinated fibers in the same three orthogonal planes. These stained-section series were from the Yakovlev-Haleem collection at the National Museum of Health and Medicine at the Armed Forces Institute of Pathology, and the Welker collection at the University of Wisconsin-Madison.

Volumetric Estimate of the Whole-Brain Weight of the Specimen

We measured the full anteroposterior extent of the brain in coronal sections with the image analysis software program Scion IMAGE for Windows (PC version of NIH IMAGE), using manually defined areas from successive slices that were integrated to yield a volumetric estimate of brain size. We converted the total volume estimate to weight units by multiplying the volume by the specific gravity of brain tissue $\left(1.036 \mathrm{~g} / \mathrm{cm}^{3}\right)$ (Stephan et al., 1981).

\section{RESULTS}

Volumetric Estimate of the Whole-Brain Weight of the Primary Specimen

The average of two measurements of whole-brain volume based on MRI was 498.5. This value is not substantially different from the fresh brain weight at necropsy. It is lower than a published estimate of brain weight from a cranial volume of $660 \mathrm{~g}$ (Marino, 2002).

\section{Neuroanatomical Description}

Figure $1 \mathrm{~A}-\mathrm{H}$ show a posterior-to-anterior sequence of originally acquired $2.0-\mathrm{mm}$-thick coronal MR brain sections at $10-\mathrm{mm}$ intervals, and a labeled schematic illustration of each section. Figure $2 \mathrm{~A}-\mathrm{H}$ display every ninth ventral-to-dorsal reconstructed horizontal section and a labeled schematic illustration of each section. Figure $3 \mathrm{~A}-\mathrm{H}$ show every sixth midline-to-lateral reconstructed sagittal section through the left hemisphere, and a labeled schematic illustration of each section.

General morphology. The figures display an excellent level of preservation of spatial relationships among the brain's structures in both the originally-acquired and reconstructed sections. Figure 3A and B show the mesencephalic and pontine flexures that resemble brainstem flexure patterns found only in the embryonic stage of terrestrial mammals. These flexures, which may be paedomorphic in nature, remain present in all adult odontocetes. Olfactory structures are absent, as is typical of adult odontocetes.

Telencephalon. Figures $1 \mathrm{C}, \mathrm{D}, \mathrm{G}$, and $\mathrm{H} ; 2 \mathrm{G}$ and $\mathrm{H}$; and $3 \mathrm{~A}-\mathrm{H}$ display the highly convoluted neocortex. The limbic and paralimbic clefts, which divide the three concentric limbic, paralimbic, and supralimbic lobes, are observable in Figures $1 \mathrm{D}-\mathrm{H}, 2 \mathrm{~F}-\mathrm{H}$, and $3 \mathrm{~B}$ and $\mathrm{C}$, respectively. Basal ganglia structures, such as the caudate, putamen, pallidum, and internal capsule, are easily visualized in Figures 1G, 2D-F, and 3B-D. Figures $1 \mathrm{G}$ and $3 \mathrm{~B}$ show the striatal fundus, where the caudate, putamen, and ventral striatum (including the nucleus accumbens) come together on the ventral surface of the hemisphere, which is a distinctive feature of cetacean brains. As is the case with other odontocete species (Morgane et al., 1980; Marino et al., 2001a, c, 2002a, b), limbic structures, such as the hippocampus, are quite small and difficult to delineate. However, also as in other odontocetes, the amygdala in S. longirostris (shown in Fig. 1F) is well developed. An interesting corollary feature to the small limbic system and corpus callosum is the elaborated cortical limbic lobe (periarchicortical field above the corpus callosum and the entorhinal cortex) (Oelschlager and Oelschlager, 2002; Marino et al., 2003b). 
As is the case with other odontocetes (Tarpley and Ridgway, 1994; Marino et al., 2001a, c, 2002a, b; Oelschlager and Oelschlager, 2002), the corpus callosum in S. longirostris is relatively thin compared to the mass of the hemispheres. This is observable in Figures $1 \mathrm{~F}$ and $\mathrm{G} ; 2 \mathrm{D}, \mathrm{F}$, and $\mathrm{G}$; and $3 \mathrm{~A}$ and $\mathrm{B}$.

Diencephalon. The odontocete diencephalon, including that of $S$. longirostris, is quite large (Marino et al., 2001a, c, 2002, 2003b). The massive thalamus can be seen in Figures $1 \mathrm{E}$ and F, 2E and F, and 3BD. The impressive size of the thalamus in cetaceans is largely, though not exclusively, due to the massive pulvinar region, which contains the medial geniculate nucleus (auditory) and the lateral geniculate nucleus (visual). Although the lateral geniculate is not as large as the medial geniculate nucleus, it is very well developed nonetheless. The hypothalamus can be seen in Figure $1 \mathrm{~F}$.

Mesencephalon. The spinner dolphin mesencephalon, which consists of the tectal region, is characterized by an outstandingly large inferior colliculus (auditory tectum). The large inferior colliculus is typical of odontocetes, and it can be at least four times as massive as the superior colliculus (visual tectum). The massive inferior colliculus is observable in Figures 1D, 2D, and 3A. The commensurately large brachium of the inferior colliculus, which projects to the medial geniculate nucleus, protrudes rather laterally and can be seen in Figure 1E. The correspondingly large lateral lemniscus can be seen in Figures $2 \mathrm{~B}$ and $3 \mathrm{C}$.

Metencephalon and myelencephalon. As is characteristic of cetaceans, the spinner dolphin cerebellum is large and well developed. This is most evident in Figures $1 A-D$ and $2 A-D$, and all of the sections in Figure 3. The combination of large cerebellar hemispheres and comparatively narrow vermis (an arrangement also typical of cetaceans) is best seen in Figures 1B-D and 2C-F.

The remainder of the hindbrain (the pons and medulla) is large and contains numerous well-developed nuclei. The size of these structures in relation to the rest of the brain is best seen in Figure $3 \mathrm{~A}$ and $\mathrm{B}$.

\section{DISCUSSION}

We have shown that the spinner dolphin brain is characterized by morphological trends similar to those found in other odontocetes (Morgane et al., 1980). This work presents the first series of MRI-based, anatomically-labeled images of the spinner dolphin (Stenella longirostris) brain. In accordance with our previous MRI-based studies of odontocete brains (Marino et al., 2001a-c, 2002, 2003a, b), the present study demonstrates the value of image-based analyses of postmortem cetacean brains. The images allow one to visualize the distinctive features of the dolphin brain from various orientations, while at the same time they preserve the spatial arrangement of structures in the specimen.

The spinner dolphin brain evinces many of the same proportions and spatial arrangements of midbrain structures found in other odontocetes. The auditory tectum (inferior colliculus) is particularly well developed. The thalamus is massive, and, consistent with the large auditory tectum, the medial geniculate nucleus is well developed. In general, the large size of the thalamus is in keeping with the massive neocortex.

As in other odontocetes, the cerebral hemispheres of the spinner dolphin show a distinctive, smoothsurfaced "lobe" (designated the "lobe desert" by Broca (1878)) on their ventral surface. The corpus striatum, caudate, putamen, accumbens, and ventral striatum all come together to make up the striatal fundus (Figures $1 \mathrm{G}$ and $3 \mathrm{~B}$ ). This feature is probably due to the absence of overlying olfactory regions plus the large size of the striatal nuclei, which in turn is due to the large size of the cerebral cortex that is being serviced by these striatal regions. 
The spinner dolphin cerebellum appears to be quite well developed. This is consistent with the finding in other odontocete species that the large cerebellum averages approximately $15 \%$ of total brain size (Marino et al., 2000). This is particularly interesting in the context of the involvement of the cerebellum in motor coordination (for review see Paulin, 1993) and the spinner dolphin's prodigious acrobatic abilities.

Relative to most other mammals, the spinner dolphin cortex exhibits a high degree of gyrification. However, it does not appear to be as finely convoluted as the cortex of odontocetes with larger brains, such as the bottlenose dolphin (Tursiops truncatus) and the beluga whale (Delphinapterus leucas), in which the average brain weights are approximately three and four times, respectively, the mass of the average spinner dolphin brain. This is consistent with a previous study by Ridgway and Brownson (1984), who found a positive relationship between surface area and brain weight among odontocetes.

The relatively small hippocampus may be partly due to a reduction in olfactory function. However, in many species the hippocampus plays an important role in memory and spatial learning (O'Keefe and Nadel, 1978). Therefore, it may be that the highly elaborated and closely associated limbic lobe reflects the transfer of hippocampus-like functions from the hippocampal domain to other cortical regions (including the periarchicortical and entorhinal regions) in the course of cetacean brain evolution. In the light of the fact that spinner dolphins appear to rely heavily on spatial learning and memory in the context of foraging and social behavior, this intriguing evolutionary possibility deserves further exploration.

\section{ACKNOWLEDGMENTS}

Susan Chivers (NMFS SEFSC, La Jolla, CA), David St. Aubin (Mystic Marine Life Aquarium, Mystic, CT), and Erin Meagher (University of North Carolina at Wilmington) assisted with the necropsy and facilitated collection of the specimen. Emory students Saima Arshad and Diana Sarko assisted with the volumetric measurement of the brain. Hui Mao (Emory University) assisted with MRI scanning at Emory Hospital. Joanne Whallon and Shirley Owen assisted in the use of the VoxelView and VoxelMath programs for digital 3D reconstructions. This study was supported by the Division of Integrative Biology and Neuroscience of the National Science Foundation (grants IBN 0131267, 0131028, and 0131826 to John I. Johnson, James T.H. Connor, and Wally Welker). William A. McLellan was supported by the National Marine Fisheries Service. 
Fig. 1. (A-H) Posterior-to-anterior sequence of originally acquired 2.0-mm thick coronal MR brain scans at 10-mm intervals and a corresponding labeled illustration of each scan.
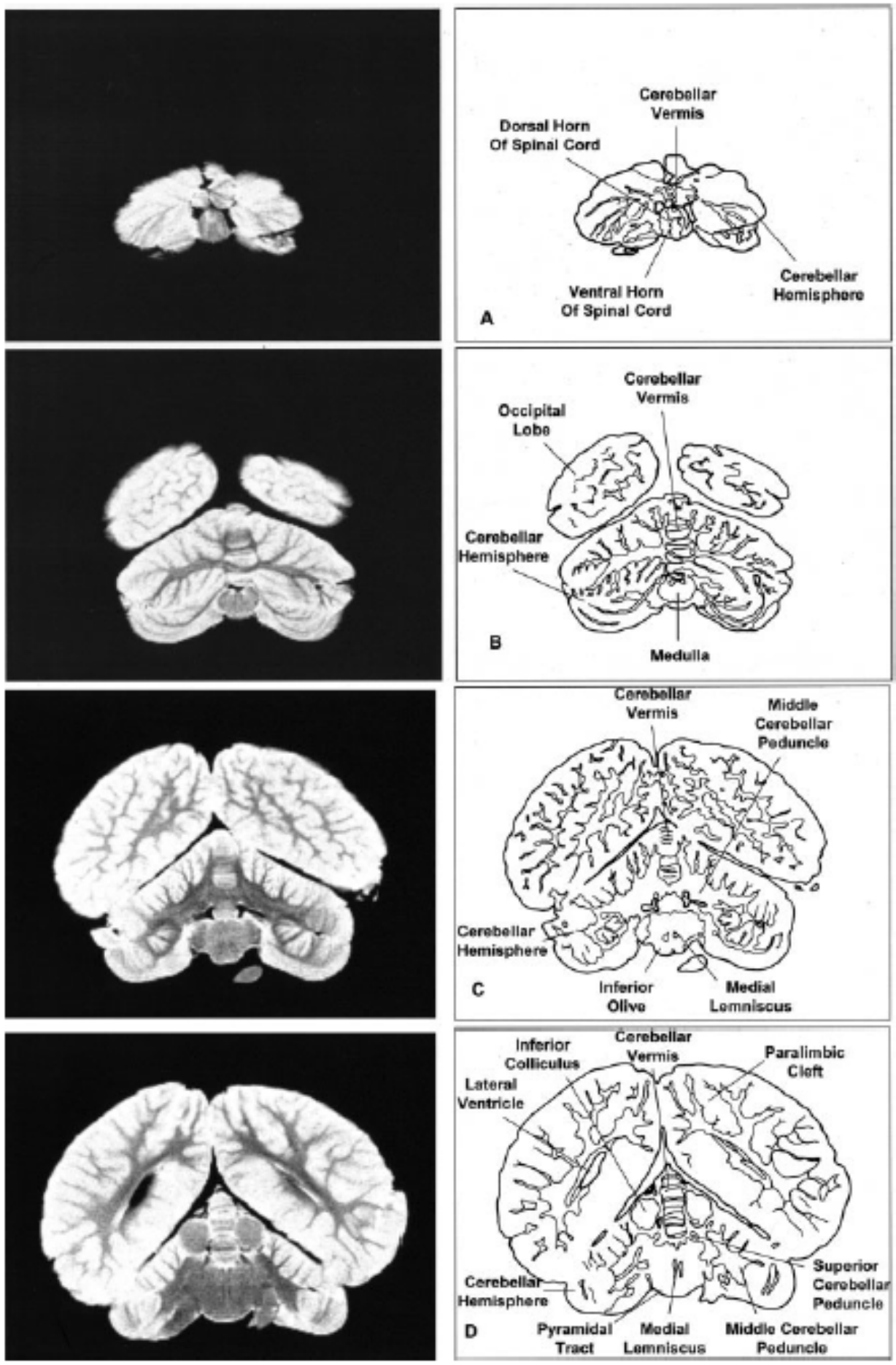
Fig. 1. (continued)
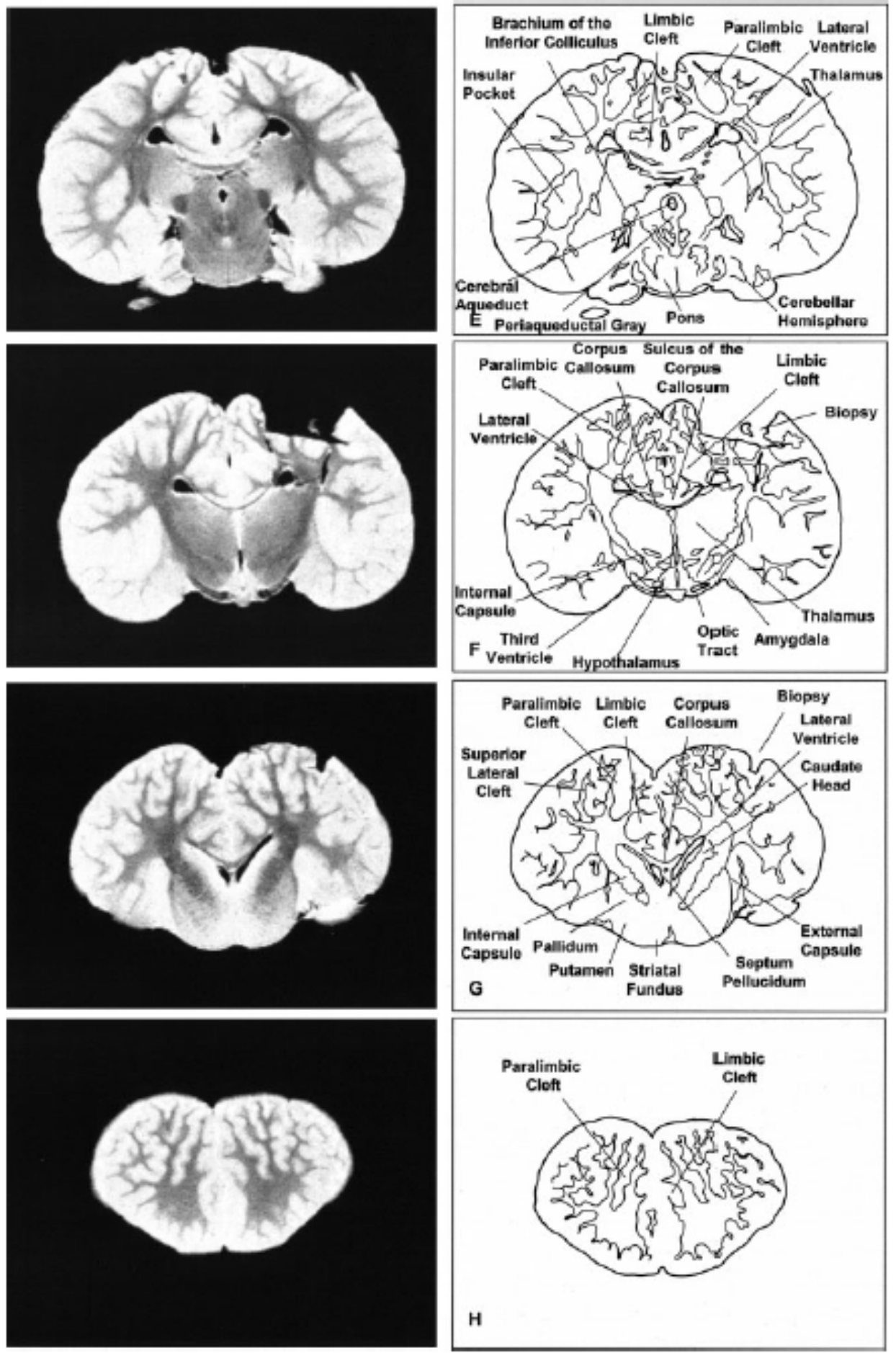
Fig. 2. (A-H) Every ninth ventral-to-dorsal reconstructed horizontal MR scan and a corresponding labeled illustration of each scan.
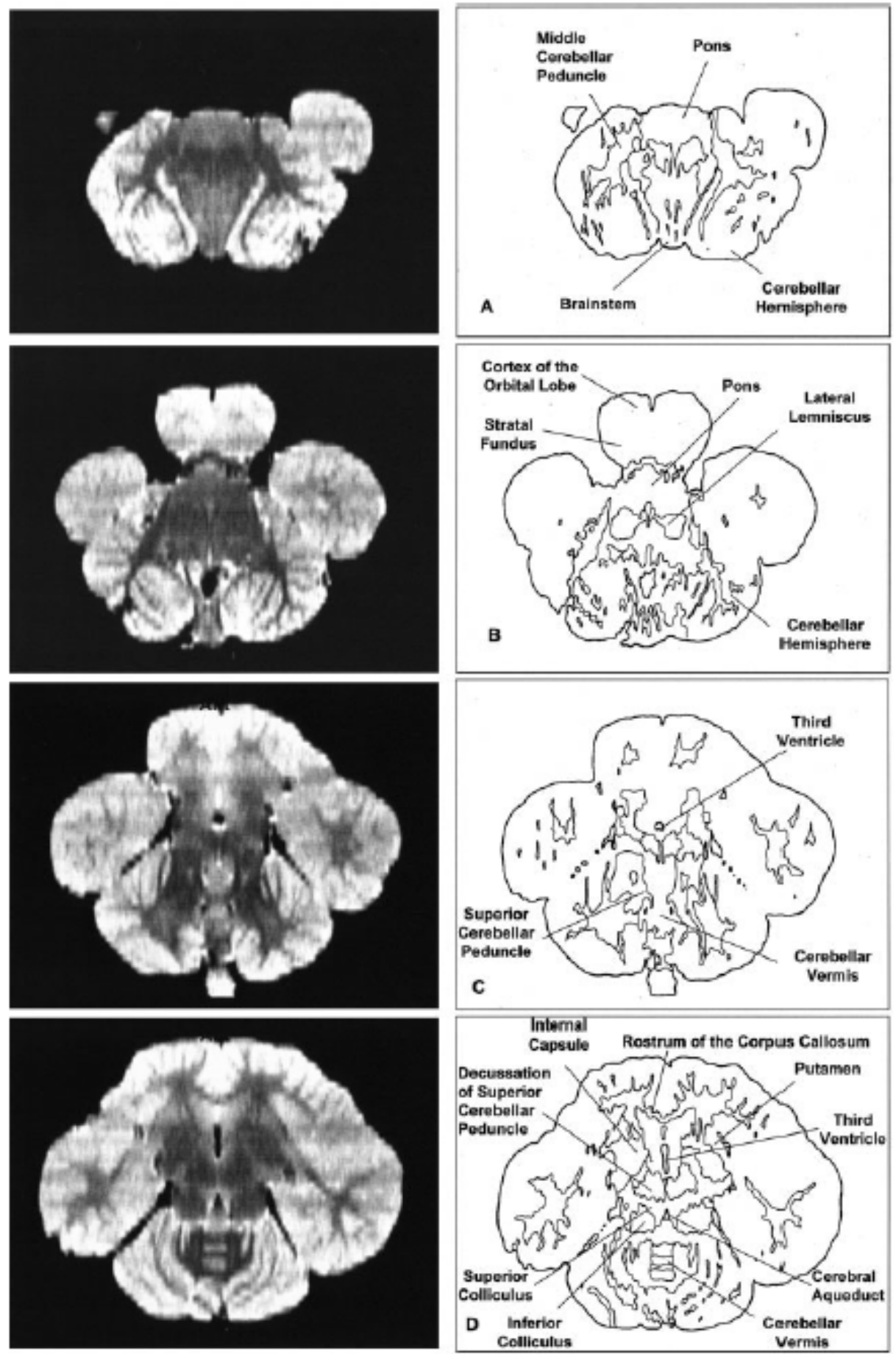
Fig. 2. (continued)
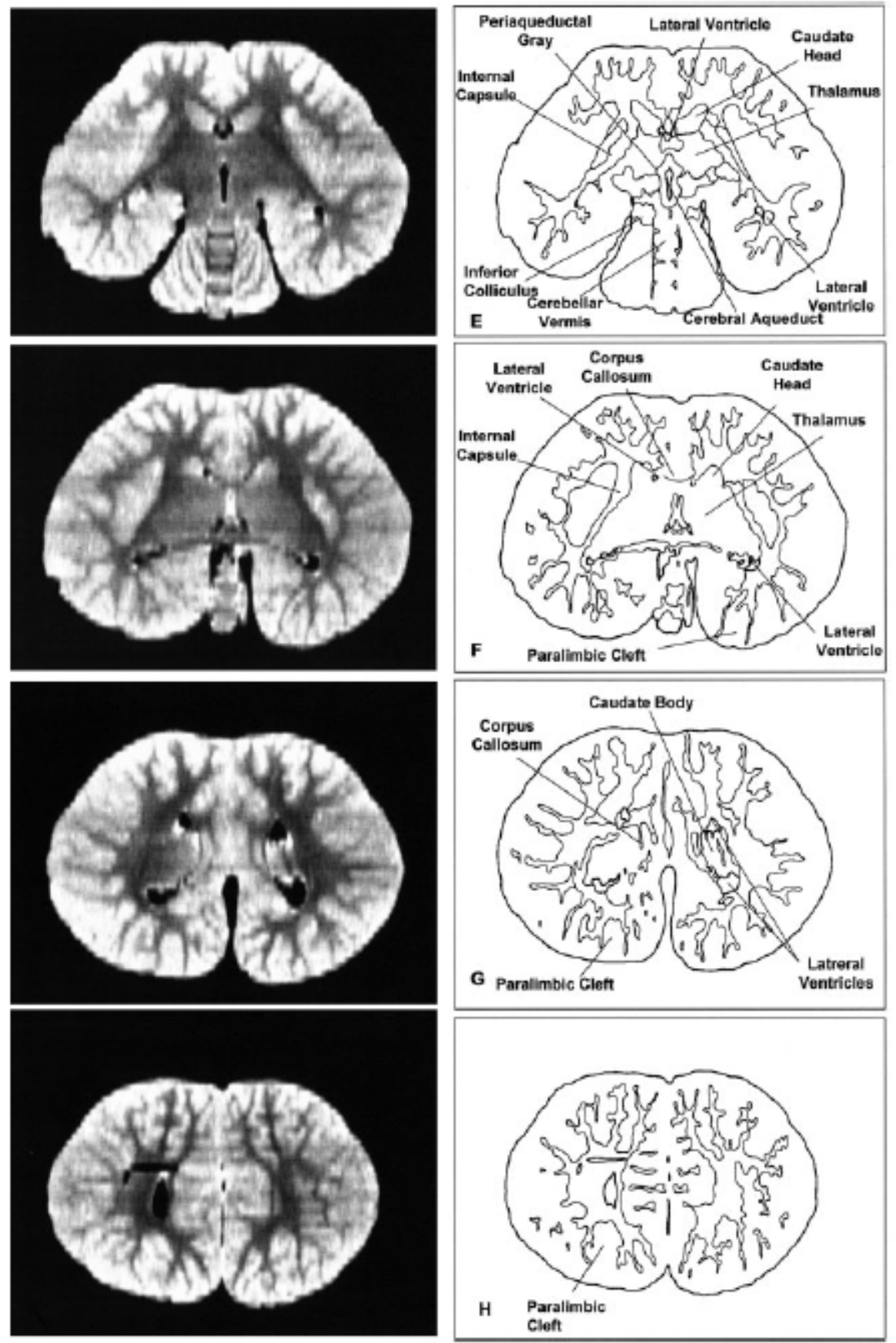
Fig. 3. (A-H) Every sixth midline-to-lateral reconstructed sagittal MR scan through the left hemisphere and a corresponding labeled illustration of each scan.
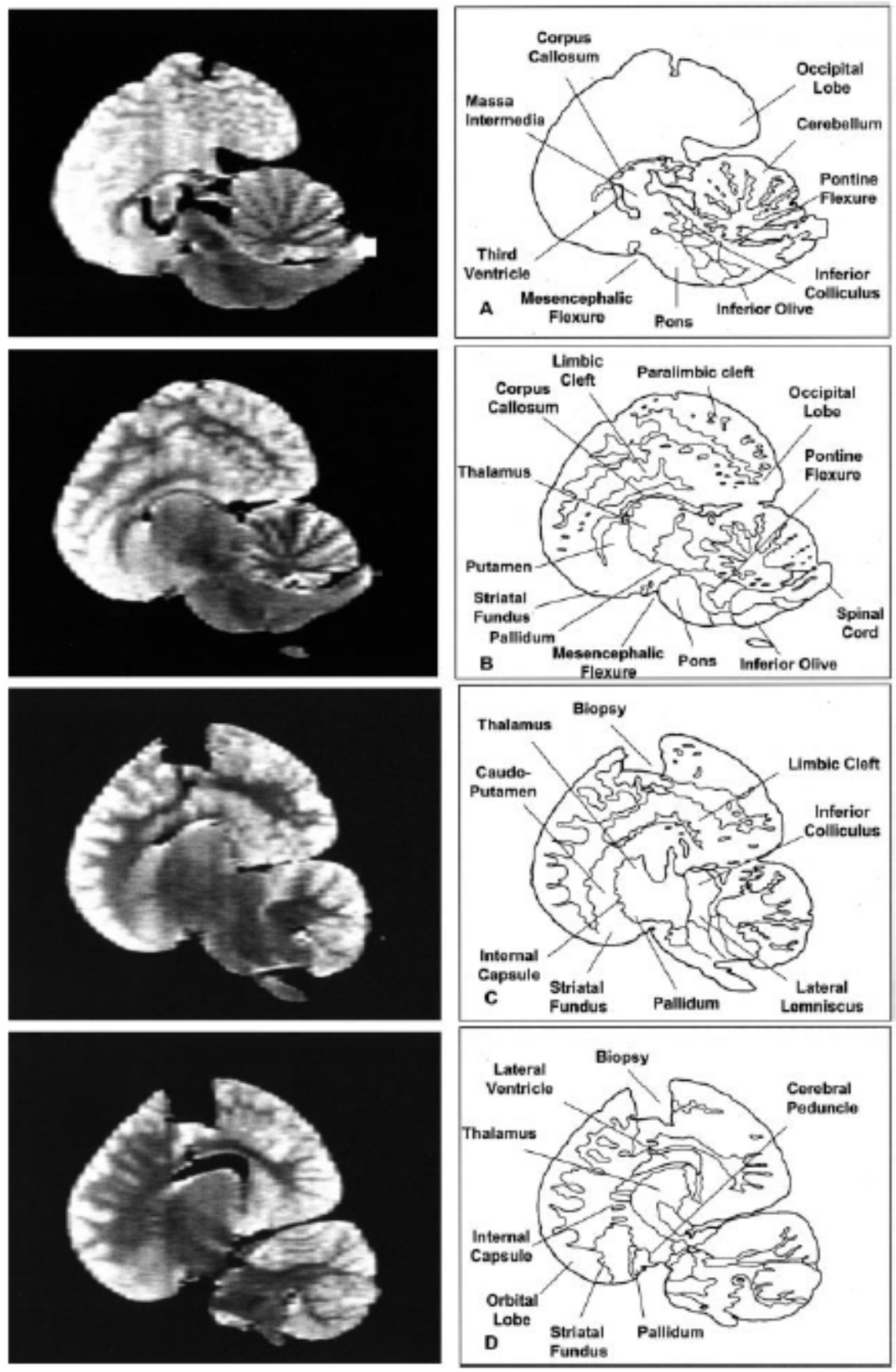
Fig. 3. (continued)
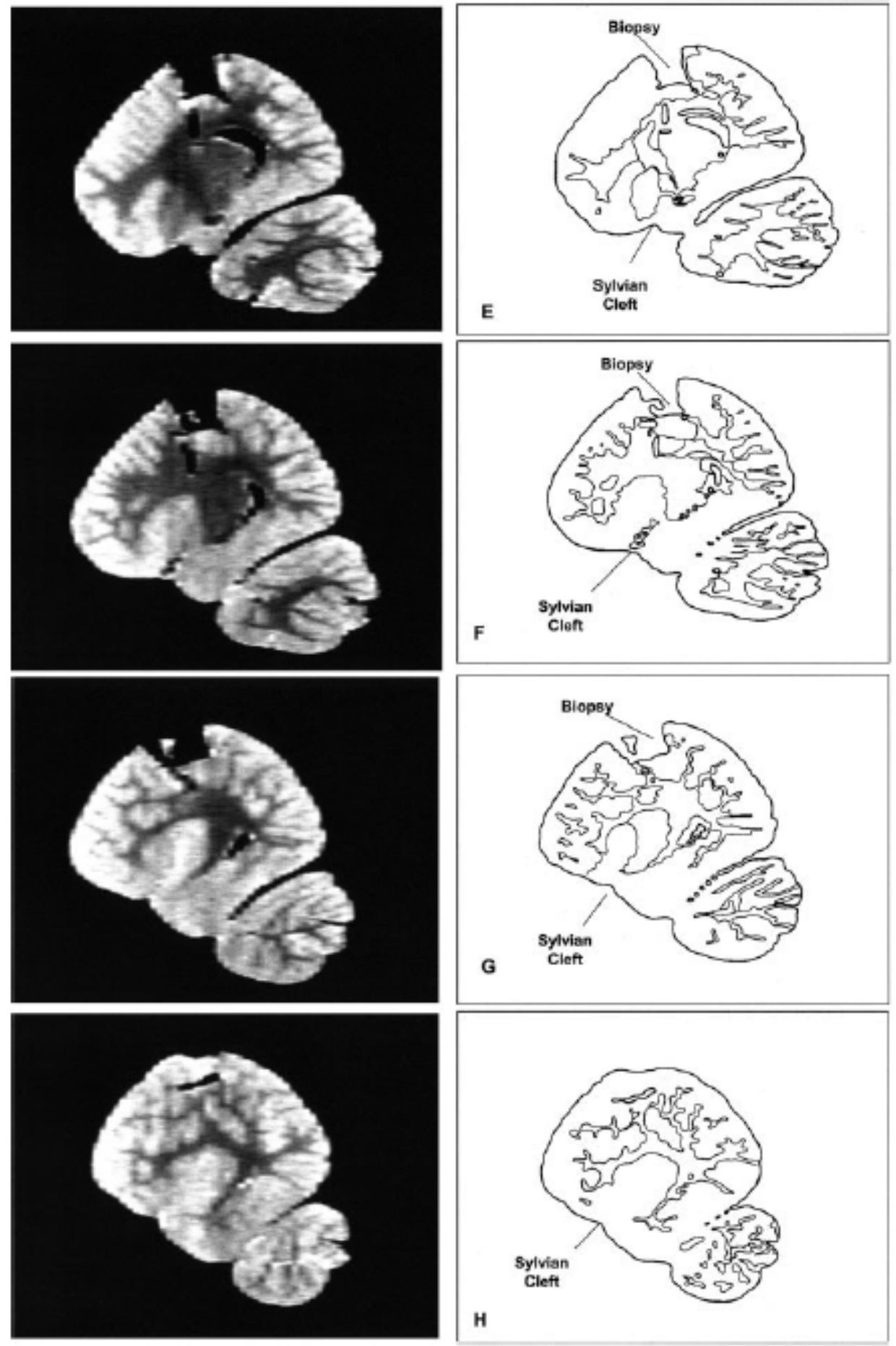


\section{LITERATURE CITED}

Broca PP. 1878. Le grand lobe limbique, et la scissure limbique dans la série de mammife 'res. Paris, France. Revue d'anthropologie, 2e se'rie. Tome 1. p 385-498.

Glezer II, Morgane PJ. 1990. Ultrastructure of synapses and golgi analysis of neurons in neocortex of the lateral gyrus (visual cortex) of the dolphin and pilot whale. Brain Res Bull 24:401-427.

Glezer II, Morgane PJ, Leranth C. 1990. Immunohistochemistry of neurotransmitters in visual cortex of several toothed whales: light and electron microscopic study. In: Thomas JA, Kastelein RA, editors. Sensory abilities of cetaceans: laboratory and field evidence. New York: Plenum Press. $p$ $39-60$.

Glezer II, Hof PR, Leranth C, Morgane PJ. 1992a. Morphological and histological features of odontocete visual neocortex: immunocytochemical analysis of pyramidal and nonpyramidal populations of neurons. In: Thomas JA, Kastelein RA, Supin AY, editors. Marine mammal sensory systems. New York: Plenum Press. p 1-38.

Glezer II, Hof PR, Morgane PJ. 1992b. Calretinin-immunoreactive neurons in the primary visual cortex of dolphin and human brains. Brain Res 595:181-188.

Glezer II, Hof PR, Leranth C, Morgane PJ. 1993. Calcium-binding protein-containing neuronal populations in mammalian visual cortex: a comparative study in whales, insectivores, bats, rodents, and primates. Cereb Cortex 3:249-272.

Glezer II, Hof PR, Istomin VV, Morgane PJ. 1995a. Comparative immunocytochemistry of calcium-binding protein-positive neurons in visual and auditory systems of cetacean and primate brains. In: Kastelein RA, Thomas JA, Nachtigall PE, editors. Sensory systems of aquatic mammals. The Netherlands: De Spil Publishers. p 477- 513.

Glezer II, Hof PR, Morgane PJ. 1995b. Cytoarchitectonics and immunocytochemistry of the inferior colliculus of midbrains in cetaceans. FASEB J 9:A247-A247.

Glezer II, Hof PR, Morgane PJ. 1999. Comparative analysis of calciumbinding protein-immunoreactive neuronal populations in the auditory and visual systems of the bottlenose dolphin (Tursiops truncatus) and the macaque monkey (Macaca fascicularis). J Chem Neurol 15:203-237.

Haug H. 1969. Vergleichende, quantitative untersuchungen an den gehiren des menschen, des elefanten und einiger zahnwale. Mediz Monat 23:201-205.

Hof PR, Glezer II, Archin N, Janssen WG, Morgane PJ, Morrison JH. 1992. The primary auditory cortex in cetacean and human brain: a comparative analysis of neurofilament protein-containing pyramidal neurons. Neurosci Lett 146:91-95.

Hof PR, Glezer II, Revishchin AV, Bouras C, Charnay Y, Morgane PJ. 1995. Distribution of dopaminergic fibers and neurons in visual and auditory cortices of the harbor porpoise and pilot whale. Brain Res Bull 36:275-284.

Hof PR, Glezer II, Conde F, Flagg RA, Rubin MB, Nimchinsky EA, Vogt Weisenhorn DM. 1999. Cellular distribution of the calciumbinding proteins parvalbumin, calbindin, and calretinin in the neocortex of mammals: phylogenetic and developmental patterns. J Chem Neurol 16:77-116. 
Hof PR, Glezer II, Nimchinsky EA, Erwin JM. 2000. Neurochemical and cellular specializations in the mammalian neocortex reflect phylogenetic relationships: evidence from primates, cetaceans, and artiodactyls. Brain Behav Evol 55:300-310.

Jacobs MS, McFarland WL, Morgane PJ. 1979. The anatomy of the brain of the bottlenose dolphin (Tursiops truncatus). Rhinic lobe (rhinencephalon): the archicortex. Brain Res Bull 4(Suppl 1):1108.

Marino L, Rilling JK, Lin SK, Ridgway SH. 2000. Relative volume of the cerebellum in the bottlenose dolphin and comparison with anthropoid primates. Brain Behav Evol 56:204-211.

Marino L, Murphy TL, Gozal L, Johnson JI. 2001a. Magnetic resonance imaging and three-dimensional reconstructions of the brain of the fetal common dolphin, Delphinus delphis. Anat Embryol 203:393-402.

Marino L, Sudheimer K, Murphy TL, Davis KK, Pabst DA, McLellan WA, Rilling JK, Johnson JI. 2001b. Anatomy and three-dimensional reconstructions of the bottlenose dolphin (Tursiops truncatus) brain from magnetic resonance images. Anat Rec 264:397-414.

Marino L, Murphy TL, DeWeerd AL, Morris JA, Fobbs AJ, Humblot N, Ridgway SH, Johnson JI. 2001c. Anatomy and three-dimensional reconstructions of the brain of the white whale (Delphinapterus leucas) from magnetic resonance images. Anat Rec 262: 429-439.

Marino L. 2002. Brain size evolution. In: Perrin WF, Wursig B, Thewissen H, editors. Encyclopedia of marine mammals. San Diego: Academic Press. p 158-162.

Marino L, Sudheimer K, Pabst DA, McLellan WA, Filsoof D, Johnson JI. 2002. Neuroanatomy of the common dolphin (Delphinus delphis) as revealed by magnetic resonance images (MRI). Anat Rec 268: 411-429.

Marino L, Sudheimer K, Sarko D, Sirpenski G, Johnson JI. 2003a. Neuroanatomy of the harbor porpoise (Phocoena phocoena) from magnetic resonance images. J Morphol 257:308-347.

Marino L, Pabst DA, McLellan WA, Sudheimer K, Johnson JI. 2003b. Magnetic resonance images of the brain of a dwarf sperm whale (Kogia simus). J Anat 204:57-76.

Morgane PJ, Jacobs MS, MacFarland WL. 1980. The anatomy of the brain of the bottlenose dolphin (Tursiops truncatus). Surface configurations of the telencephalon of the bottlenose dolphin with comparative anatomical observations in four other cetacean species. Brain Res Bull 5:107.

Morgane PJ, Glezer II, Jacobs MS. 1990. Comparative and evolutionary anatomy of the visual cortex of the dolphin. In: Jones EG, Peters A, editors. Cerebral cortex. Vol. 8b. Plenum Publishing. p 215262.

Oelschlager HA, Oelschlager JS. 2002. Brains. In: Perrin WF, Wursig B, Thewissen H, editors. Encyclopedia of marine mammals. San Diego: Academic Press. p 133-158.

O'Keefe J, Nadel I. 1978. The hippocampus as a cognitive map. Oxford: Clarendon 570 p.

Paulin MG. 1993. The role of the cerebellum in motor control and perception. Brain Behav Evol 41:39-50. 
Perrin WF. 1975. Variation of spotted and spinner porpoise (genus Stenella) in the eastern tropical Pacific and Hawaii. Berkeley: University of California Press. 206 p.

Ridgway SH, Brownson RH. 1984. Relative brain sizes and cortical surface areas in odontocetes. Acta Zool Fenn 172:149-152.

Ridgway SH, Marino L, Lipscomb T. 2002. Description of a poorly differentiated carcinoma within the brainstem of a white whale (Delphinapterus leucas) from magnetic resonance images and histological analysis. Anat Rec 268:441-449.

Stephan H, Frahm H, Baron G. 1981. New and revised data on volumes of brain structures in insectivores and primates. Folia Primatol 25:1-29.

Tarpley RJ, Ridgway SH. 1994. Corpus callosum size in delphinid cetaceans. Brain Behav Evol 44:156165. 